Published in final edited form as:

Cancer Nurs. 2018 ; 41(6): 491-497. doi:10.1097/NCC.0000000000000556.

\title{
Quality of Life in Partners of Young and Old Breast Cancer Survivors
}

\author{
Andrea A. Cohee, Ph.D., Silvia M. Bigatti, Ph.D., Cleveland G. Shields, Ph.D., Shelley A. \\ Johns, Psy.D. ABPP, Timothy Stump, M.S., Patrick O. Monahan, Ph.D., and Victoria L. \\ Champion, Ph.D. \\ Indiana University School of Nursing, Indianapolis, Indiana (Drs. Cohee and Champion); Indiana \\ University School of Public Health, Indianapolis, Indiana (Dr. Bigatti); Purdue University, Lafayette, \\ Indiana (Dr. Shields); Indiana University School of Medicine and Regenstrief Institute (Dr. Johns); \\ Department of Biostatistics, Indiana University School of Medicine, Indianapolis, Indiana (Mr. \\ Stump and Dr. Monahan)
}

\begin{abstract}
Background-Partners of breast cancer survivors experience the effects of a spouse's cancer years after treatment. Partners of younger survivors (YP) may experience greater problems than partners of older survivors (OP), just as younger survivors experience greater problems than their older counterparts.
\end{abstract}

Objectives-To 1) compare quality of life (QoL) in YP and OP, and 2) determine contributing factors to each group's QoL.

\begin{abstract}
Methods-Cross-sectional data were collected from YP ( $n=227)$ and OP $(n=281)$ through selfreport. MANOVA was used to determine differences between YP and OP on QoL while controlling for covariates. Multiple regression analyses were conducted to determine what contributes to each group's QoL.
\end{abstract}

\begin{abstract}
Results-YP reported better physical function (effect size $(E S)=-0.57$ ), lower marital satisfaction ( $\mathrm{ES}=0.39)$, and lower overall QoL $(\mathrm{ES}=0.43$ ) than partners of older survivors. Predictors of QoL also differed between partner groups. For YP, overall QoL was predicted by greater physical functioning, fewer depressive symptoms, higher marital satisfaction, higher parenting satisfaction, and more personal resources. $\mathrm{R}^{2}=.47 ; \mathrm{F}(5,195)=35.05 ; \mathrm{p}<.001$. For OP, overall QoL was predicted by fewer depressive symptoms, higher parenting satisfaction, higher spirituality, and greater social support from the breast cancer survivor spouse. $\mathrm{R}^{2}=.33 ; \mathrm{F}(4,244)=$ 29.80; $\mathrm{p}<.001$.
\end{abstract}

Conclusions-OP reported greater QoL than YP. Common factors contributing to QoL between YP and OP were fewer depressive symptoms and higher parenting satisfaction.

An estimated 2.9 million women are living with a history of breast cancer in the United States. ${ }^{1}$ For a large percentage of these survivors, the experience of breast cancer has left

Correspondence: Andrea Cohee, PhD, Indiana University School of Nursing, 600 Barnhill Drive, NU 317, Indianapolis, IN 46202 (aamaners@iu.edu).

The authors have no conflicts of interest to disclose. 
them with physical and psychological sequelae that affect their quality of life. ${ }^{2}$ Breast cancer survivors often report problems lasting years after diagnosis and treatment, including: sleep difficulties, fatigue, depression, poor attention and sexual functioning, and fear of recurrence. ${ }^{2}$ Furthermore, the partners of breast cancer survivors also express concerns that include higher levels of distress and more unmet needs than their survivor spouse. ${ }^{3-5}$

Past research has documented the effect of a breast cancer diagnosis and treatment on partners. In one study, compared to partners of women without disease, partners of breast cancer patients scored lower on the general health, vitality, role-emotional and mental health subscales of the MOS SF-36, a quality of life measure. ${ }^{6}$ Partners of breast cancer survivors consistently report higher levels of anxious and depressive symptomatology than partners of healthy controls, with partners of breast cancer survivors reporting poor social, psychological, physical, and general quality of life. Partners of patients undergoing treatment also report higher scores on measures of depression and anxiety than controls. ${ }^{6,7}$ One published study from national health record data in Denmark reported partners of breast cancer survivors had an increased odds ratio of 1.08 (95\% CI, 1.03-1.13) for first use of antidepressant medication during a spouse's treatment compared to the general population. ${ }^{8}$ Furthermore, these partners were at an increased risk of using depression medication for up to 14 years after treatment. ${ }^{8}$

Some literature indicates age and life stage are associated with adjustment to cancer. Previous studies reported that young to middle-aged survivors experience more psychological stress than older survivors, in part due to decreased fertility following treatment, having young children at home, not expecting to have a serious illness at a young age, and job stressors. ${ }^{9,10}$ Furthermore, among the survivors in this study, younger age was associated with lower body image, worse sleep, worse marital satisfaction and higher anxiety and fear of recurrence. ${ }^{2}$ There is some evidence that the risk of depression in partners increases with age; ${ }^{8}$ however, no other long-term outcomes for partners of younger and older survivors have previously been reported. Given the findings that younger survivors suffer disproportionately compared to older survivors and the limited information on outcomes in partners, the goal of this secondary analysis was to determine if the partners of the younger survivors report lower quality of life than partners of older survivors. A second goal was to determine contributing factors to each partner group's long-term quality of life. Identifying the unique experiences for partners of younger and older survivors may be useful for clinicians to meet the personalized needs of these partners following treatment.

\section{Theoretical Framework}

The City of Hope Quality of Life Model, which guided the parent study, posits four domains (physical, psychological, social, and spiritual) of well-being contribute to a person's overall quality of life. Physical well-being is described as "the maintenance of function and independence. ${ }^{11 "}$ Social well-being encompasses the relationship between the survivor and the partner as well as the partner's personal resources such as social support. Psychological well-being is described as, "seeking a sense of control in the face of life threatening illness. Psychological well-being includes emotional distress such as depression and anxiety, fear and positive or negative life changes. ${ }^{12}$ " Finally, spiritual well-being is characterized in 
terms of existential and religious dimensions. ${ }^{12}$ In order to evaluate quality of life (QoL) for partners of cancer survivors, all domains were assessed.

This aim of this study, then, was to examine the long-term quality of life in partners of breast cancer survivors by (1) comparing partners of younger survivors to partners of older survivors on all quality of life domains (physical, psychological, social, and spiritual wellbeing) and (2) examining what factors (i.e. physical, psychological, social, and spiritual wellbeing) contributed to each group's overall quality of life.

\section{Methods}

\section{Participants}

Approach—Data for this study were taken from a larger QoL study of breast cancer survivors recruited from the Eastern Cooperative Oncology Group (ECOG-ACRIN), acquaintance controls, and partners for each group. Study inclusion criteria, recruitment procedures, and results for survivors and acquaintances have been previously reported. ${ }^{2}$ Younger and older survivors and acquaintance controls were compared on a host of variables used to operationalize physical, psychological, social, and spiritual wellbeing and as well as overall QoL. The purpose of the parent study was to compare long-term QoL in younger survivors (women diagnosed with breast cancer at age 45 years or younger) to both agematched controls and older survivors (women diagnosed with breast cancer ages 55-70) who had been diagnosed 3-8 years prior. Women ages 46-54 at diagnosis were excluded to minimize potential confounders of perimenopausal symptoms. Survivors had to have received chemotherapy as part of their treatment and be disease free without a recurrence at the time of participation. Partners/spouses for each group were invited to participate and completed surveys assessing their quality of life. The only requirement for partners' inclusion was that they self-identify as such. Because of this, partner groups were dependent on survivors' age at diagnosis rather than their own chronological age. ${ }^{2}$

Participants-For this secondary analysis, participants included 227 partners of young survivors and 281 partners of older survivors. Partners of acquaintance controls from the parent grant were excluded from these analyses because the intent was to determine QoL differences between partner groups based on when breast cancer survivors (BCS) were diagnosed with cancer.

\section{Measures}

Socio-demographic information was collected for partners of younger breast cancer survivors (YP) and partners of older breast cancer survivors (OP) and included current age, education, race, and religious affiliation. Time since diagnosis was also used to analyze partners' data. Quality of life, as measured by four domains of wellbeing proposed by Ferrell and colleagues, ${ }^{11,12}$ were measured with the following scales (see Figure for the QoL model).

Physical well-being-This domain consisted of measures of physical functioning including sexual functioning. Physical well-being was measured by the Physical Functioning 
Scale (PF-10). ${ }^{13}$ Sexual Functioning was measured with a physical and a social component which is described under the social domain. The physical Sexual Difficulty subscale asks about the participant's difficulty in becoming aroused, maintaining an erection, and having an orgasm.

Social well-being - This domain consisted of measures of sexual enjoyment, marital satisfaction, social support from partner and from one's social network, and social constraint from a spouse. The social component of the sexual functioning scale measured Sexual Enjoyment. The subscale asks the participant about interest in sexual activities, ability to relax and enjoy activities, satisfaction with frequency of activities, and frequency of sexual thoughts or fantasies. The partnered relationship was measured by the Marital Satisfaction Scale (ENRICH MSS), a 15-item scale with previously reported validity and reliability. ${ }^{14}$ Social support from the spouse was measured by the Northouse Social Support Scale. ${ }^{15}$ The scale measures perceived social support from a spouse. Social Constraints were measured using 14 items from the Lepore Social Constraints Scale, which asks participants how often the participant perceived constraining behaviors from his/her partner in the last four weeks.

${ }^{16}$ Personal Resource Questionnaire measures support from other people such as friends, coworkers, relatives, and anyone else in the participant's social network. ${ }^{17}$

Psychological well-being-This domain measure levels of depressive symptomatology and trauma. Depressive symptoms were measured using the Centers for Epidemiologic Studies-Depression Scale, ${ }^{18}$ a 20 -item summated scale with scores above 16 being consistent with clinical depression (range 0-60). The Impact of Events Scale- Revised (IES$R$ ) is composed of 3 subscales: hyperarousal, cognitive avoidance, and intrusive thoughts. A total score of the 3 subscales can be used as an indicator of a stress response. ${ }^{19}$

Spiritual well-being-The REED Spiritual Perspectives Scale is composed of 10 items, 4 describing spiritual behaviors and 6 describing spiritual beliefs. ${ }^{20}$ Mean values are calculated. Responses range 1-6 for each item.

Overall quality of life-Overall QoL was measured by the Index of Well-Being (IWB). ${ }^{21}$ The 7 items ask about how the participant feels about his/her life in general.

\section{Statistical Analysis}

All analyses were conducted using SPSS $23 .{ }^{22}$ Descriptive statistics, including frequencies and measures of central tendency, were analyzed for age, race, education, and religious affiliation. Multivariate analyses of variance examined differences by group. In order to determine differential impact of cancer by age/life stage, QoL domains were compared between the partners of younger versus older long-term survivors. For statistically significant differences, effect sizes of 0.33 or higher were deemed clinically significant. ${ }^{23}$ Secondly, regression analyses using a backward selection process were conducted separately for YP and OP to determine contributing factors of overall QoL for each group. 


\section{Results}

Participants were predominantly Caucasian, well educated, and Christian. See Table 1 for complete demographic information by group. Significant differences did exist between groups. Racially, the YP group was composed of more African Americans and those who identified as "other" than OP. Racial option choices included: Caucasian, Black/African American, Asian, and Other. More YP reported no religious affiliation than OP. Age ranges overlapped between partner groups, but OP were older than YP (mean age of 68 years for $\mathrm{OP}$ and 48 years for $\mathrm{YP}$ ). Time since diagnosis ( $\mu=5.8$ years, $\mathrm{SD}=1.5$ years) was not significantly related to any partner variable.

\section{QoL Differences Between Partner Groups}

All MANOVA contrasts controlled for age and whether or not the partner was in a relationship with the survivor at time of diagnosis, 3-8 years prior to data collection. Results are presented in Table 2. Statistically significant differences were observed in each QoL domain; however, the majority of the significant findings had effect sizes smaller than those previously described as being clinically significant. Several contrasts between YP and OP met this threshold. In comparing partners of younger versus partners of older BCS, YP reported, as indicators of physical functioning: better physical function $(\mathrm{ES}=-0.57)$ on the PF10 and less sexual functioning difficulty ( $E S=-0.82)$; as indicators of social functioning: lower marital satisfaction ( $\mathrm{ES}=0.39)$ and greater total sexual functioning $(\mathrm{ES}=-0.61)$; as an indicator of psychological wellbeing: more hyperarousal ( $E S=-0.33$ ); and as an indicator of overall QoL: lower overall QoL (ES=0.43) than OP.

\section{Predictors of Quality of Life}

For YP, overall QoL was predicted in the regression analysis by variables in the physical, psychological, and social domains of wellbeing, including: greater physical functioning, fewer depressive symptoms, higher marital satisfaction, higher parenting satisfaction, and more personal resources $\left(\mathrm{R}^{2}=.47 ; \mathrm{F}(5,195)=35.05 ; \mathrm{p}<.001\right)$. Details for YP regression analysis are presented in Table 3 .

Overall QoL for OP was predicted in the regression analysis by variables in the psychological, spiritual, and social domains of wellbeing, including: fewer depressive symptoms, higher spirituality, higher parenting satisfaction, and greater social support from the BCS spouse $\left(\mathrm{R}^{2}=.33 ; \mathrm{F}(4,244)=29.80 ; \mathrm{p}<.001\right)$. Results of the regression for OP are presented in Table 4.

\section{Discussion}

The goal of this study was to examine the long-term QoL impact of spouses' breast cancer. There were two aims. First, comparisons were drawn between partners of BCS diagnosed earlier in life and partners of BCS diagnosed later in life. Second, contributing factors to overall QoL in both partners of younger BCS and partners of older BCS were identified. In comparing partners of younger versus partners of older BCS, several clinically significant contrasts were evident: YP reported better physical and sexual function with 
lower sexual functioning difficulty, but lower marital satisfaction, more hyperarousal, and lower overall QoL than OP. Predictors of QoL also varied between YP and OP groups.

In this sample, YP reported better overall physical function as measured on the PF10, which is to be expected in the normal life course, as physical functioning decreases with age. ${ }^{24}$ Physical functioning also predicted QoL in YP but not in OP. Important to mention is the fact that OP generally reported high levels of physical function (more than 50\% reporting "little" or "no" physical functioning limitations), which may have exceeded their expectations in old age. In a sample of more than 79,000 older Australian men of similar ages to this sample, about $27 \%$ reported moderate-severe physical limitation compared to $8.6 \%$ in the present sample. ${ }^{25}$ Similarly, unsurprising were the findings that YP reported better overall sexual functioning and lower sexual functioning difficulty, as these findings are similar to those of nationally representative samples. ${ }^{26}$

In the current study, YP reported lower marital satisfaction than OP. During the normal life course, marital satisfaction increases later in life, presumably after children have left home and couples have more quality time to spend together. ${ }^{27}$

Finally, YP reported worse overall wellbeing than OP, which is consistent with previous research. Other studies have reported that life satisfaction and wellbeing are stable ${ }^{28}$ and possibly increase over the life course. ${ }^{29}$

\section{Predicting Well-being in YP and OP}

There were some commonalities but also distinct differences between partner groups in terms of which variables predicted wellbeing in this study. For both groups, experiencing few depressive symptoms and high parenting satisfaction were significant predictors of wellbeing. The negative relationship between depressive symptoms and wellbeing is well established, ${ }^{30}$ as the key components of depression are disrupted functioning in all life domains. ${ }^{31}$ On the measure of depressive symptoms in this study, the Centers for Epidemiologic Studies-Depression scale (CES-D), a clinically significant score consistent with a diagnosis of depression is generally defined as a score at or above $16 .^{32}$ While the mean scores on the CES-D were low for each group ( $\mu=8.795, \mathrm{SD}=8.486$ for YP and $\mu=6.881, \mathrm{SD}=6.024$ for $\mathrm{OP}), 7.6 \%$ of YP and $6.5 \%$ of partners of older survivors met the threshold criteria for clinical depression.

Parenting satisfaction has previously been linked with QoL outcomes in older adults. ${ }^{33} \mathrm{OP}$ were more satisfied with their ability to "be a good parent to my children" and were less likely to feel that "problems in my life interfere with my ability to be a good parent." No differences were noted in either group or between groups if children were currently living at home or outside the home. Having trusting relationships with children and not being dependent on children predicted wellbeing in a large, longitudinal British study of QoL in older adults. ${ }^{33}$ Parenting satisfaction differed slightly between YP and OP, with OP reporting higher parenting satisfaction. Only two questions of the five were significantly different: "I am satisfied with my ability to be a good parent to my children," and "problems in my life interfere with my ability to be a good parent." 
Several predictors of QoL differed between YP and OP. For YP, overall QoL was predicted by wellbeing in nearly all quality of life domains identified by Ferrell and colleagues. ${ }^{11,12}$ The only domain that partners of younger survivors did not identify as a priority to their QoL was spirituality. According to Pew research, religiosity is decreasing in younger generations in the United States, ${ }^{34}$ making this finding not entirely surprising. Partners of younger survivors identified physical functioning, mental health (experiencing fewer depressive symptoms), marital satisfaction, parenting satisfaction, and a variety of personal resources as necessary for overall QoL. Partners of younger survivors may have a lower threshold for coping with problematic situations and therefore need stability in all domains of QoL. According to Life Course Theory, the timing of an event can impact the meaning of that event. ${ }^{35} \mathrm{~A}$ traumatic event such as a young spouse's cancer may disrupt the partner's sense of agency (control) at a time of career and social development.

OP differed from YP in that higher spirituality and greater social support predicted QoL. In a longitudinal study of older adults, Cowlishaw and colleagues (2013) found spirituality was associated with subjective wellbeing over time. ${ }^{36}$ The relationship was mediated by "meaning," which the authors described as the view that adversities are seen as challenges and worthy of engagement. ${ }^{36}$ It may be that older partners view adversities (such as a spouse's breast cancer) as challenges and engage spirituality as a tool toward their wellbeing. Also for older adults, receiving social support from a spouse is related to QoL more so than receiving social support from others in their social network. ${ }^{37}$ In this sample, OP reported significantly higher levels of social support from BCS than did YP, yet there was no difference in perceived support provided by social networks.

\section{Limitations}

While this large dataset provided a unique opportunity to contrast partners of younger, longterm BCS and partners of older, long-term BCS, several limitations must be noted. First, data from this study were taken from a cross-sectional non-experimental design, limiting the possibility of drawing causal conclusions. Longitudinal data would provide the opportunity to gauge how the cancer experience impacted QoL over time and specifically by life stage. Second, the selected survivor groups (women ages 45 and younger and women ages 55-70) which determined the current sample may have missed an important group of partners of women ages 46-54 when diagnosed with breast cancer. Third, without data prior to the cancer diagnosis, a determination cannot be made if the partners of younger BCS and partners of older BCS differed in any way prior to a cancer experience. Fourth, the sample was primarily Caucasian and more highly educated than the average American, and thus possibly not representative of the larger population. Furthermore, the survey did not ask partners to disclose income data, which may have been an important factor in their QoL.

\section{Conclusions}

Partners of younger survivors and partners of older survivors differed in several important dimensions of overall QoL. Most notably, partners of younger survivors reported better physical function, but lower marital satisfaction and overall QoL than partners of older survivors. Partners of younger survivors may need psychological counseling to deal with the 
many stressors associated with their life stage. Nurses caring for breast cancer survivors and their partners should understand several clinical implications. First, it is important to include partners and their needs in any survivorship care plan. For instance, both YP and OP experience depressive symptoms years after their spouses' breast cancer diagnosis and may need psychological counseling referrals. Secondly, it is likely that YP will have more difficulty with sexual functioning and marital satisfaction, thus the dyadic relationship could suffer. Education on possible adjustments for sexual activity may improve functioning. For YP especially, it will be important to stress clear communication between spouse and partner and when necessary, refer couple for counseling. This study emphasizes the need to understand that the family as a unit is impacted by a breast cancer diagnosis and partners will impact overall trajectory for survivors.

\section{Acknowledgments}

This study was coordinated by the ECOG-ACRIN Cancer Research Group (Robert L. Comis, MD and Mitchell D. Schnall, MD, PhD, Group Co-Chairs) and supported in part by Public Health Service Grants CA189828, CA180795, CA37403, CA35199, CA17145 and CA49883, and from the National Cancer Institute, National Institutes of Health and the Department of Health and Human Services. Its content is solely the responsibility of the authors and does not necessarily represent the official views of the National Cancer Institute.

Research reported in this publication was supported by the National Cancer Institute of the National Institutes of Health under Award Numbers K05CA175048, T32CA117865-11, and R25CA117865. Its content is solely the responsibility of the authors and does not necessarily represent the official views of the National Institutes of Health, including the National Cancer Institute or the National Institute of Nursing Research.

\section{References}

1. Siegel RL, Miller KD, Jemal A. Cancer statistics, 2015. CA: a cancer journal for clinicians. 2015; 65(1):5-29. [PubMed: 25559415]

2. Champion VL, Wagner LI, Monahan PO, et al. Comparison of younger and older breast cancer survivors and age- matched controls on specific and overall quality of life domains. Cancer. 2014; 120(15):2237-2246. [PubMed: 24891116]

3. Braun M, Mikulincer M, Rydall A, Walsh A, Rodin G. Hidden morbidity in cancer: spouse caregivers. Journal of Clinical Oncology. 2007; 25(30):4829-4834. [PubMed: 17947732]

4. Nakaya N, Saito-Nakaya K, Bidstrup PE, et al. Increased risk of severe depression in male partners of women with breast cancer. Cancer. 2010

5. Moreira H, Canavarro MC. Psychosocial adjustment and marital intimacy among partners of patients with breast cancer: a comparison study with partners of healthy women. Journal of psychosocial oncology. 2013; 31(3):282-304. [PubMed: 23656256]

6. Litzelman K, Yabroff KR. How are spousal depressed mood, distress, and quality of life associated with risk of depressed mood in cancer survivors? Longitudinal findings from a national sample. Cancer Epidemiology Biomarkers \& Prevention. 2015; 24(6):969-977.

7. Wagner CD, Bigatti SM, Storniolo AM. Quality of life of husbands of women with breast cancer. Psycho- Oncology. 2006; 15(2):109-120. [PubMed: 15852406]

8. Cromhout PF, Latocha KM, Olsen MH, et al. First use of antidepressant medication in male partners of women with breast cancer in Denmark, 1998-2011. Psycho- Oncology. 2017

9. Reyes-Gibby CC, Anderson KO, Morrow PK, Shete S, Hassan S. Depressive symptoms and healthrelated quality of life in breast cancer survivors. Journal of Women's Health. 2012; 21(3):311-318.

10. Gorman JR, Malcarne VL, Roesch SC, Madlensky L, Pierce JP. Depressive symptoms among young breast cancer survivors: the importance of reproductive concerns. Breast cancer research and treatment. 2010; 123(2):477-485. [PubMed: 20130979]

11. Ferrell BR, Grant M, Funk B, Otis-Green S, Garcia N. Quality of life in breast cancer: Part I: Physical and social well-being. Cancer nursing. 1997; 20(6):398. [PubMed: 9409061] 
12. Ferrell BR, Grant M, Funk B, Otis-Green S, Garcia N. Quality of life in breast cancer: Part II: Psychological and spiritual well-being. Cancer nursing. 1998; 21(1):1. [PubMed: 9494225]

13. Haley SM, McHorney CA, Ware JE. Evaluation of the MOS SF-36 physical functioning scale (PF-10): I. Unidimensionality and reproducibility of the Rasch item scale. Journal of clinical epidemiology. 1994; 47(6):671-684. [PubMed: 7722580]

14. Fowers BJ, Olson DH. ENRICH Marital Satisfaction Scale: A brief research and clinical tool. Journal of Family Psychology. 1993; 7(2):176.

15. Northouse LL, Templin T, Mood D, Oberst M. Couples' adjustment to breast cancer and benign breast disease: a longitudinal analysis. Psycho- Oncology. 1998; 7(1):37-48. [PubMed: 9516649]

16. Lepore SJ. A Social-Cognitive Processing Model of Emotional Adjustment to Cancer. In: Baum BLA A, editorPsychosocial Interventions for Cancer. Washington, D.C: American Psychological Association; 2001. 99-116.

17. Brandt PA, Weinert C. The PRQ-a social support measure. Nursing research. 1981; 30(5):277-280. [PubMed: 7027186]

18. Radloff LS. The CES-D Scale: A Self Report Depression Scale for Research in the General. Applied psychological measurement. 1977; 1(3):385-401.

19. Creamer M, Bell R, Failla S. Psychometric properties of the impact of event scale-revised. Behaviour research and therapy. 2003; 41(12):1489-1496. [PubMed: 14705607]

20. Reed PG. Spirituality and well-being in terminally ill hospitalized adults. Research in nursing \& health. 1987; 10(5):335-344. [PubMed: 3671781]

21. Campbell A, Converse PE, Rogers WL. The quality of American life: Perceptions, evaluations, and satisfactions. New York, NY: Russell Sage Foundation; 1976.

22. SPSS Statistics for Windows [computer program]. Version Version 24. Armonk, NY: IBM Corporation; 2016.

23. Bishop MM, Beaumont JL, Hahn EA, et al. Late effects of cancer and hematopoietic stem-cell transplantation on spouses or partners compared with survivors and survivor-matched controls. Journal of Clinical Oncology. 2007; 25(11):1403-1411. [PubMed: 17416860]

24. Milanović Z, Pantelić S, Trajković N, Sporiš G, Kostić R, James N. Age-related decrease in physical activity and functional fitness among elderly men and women. Clinical interventions in aging. 2013; 8:549. [PubMed: 23723694]

25. Yorston LC, Kolt GS, Rosenkranz RR. Physical activity and physical function in older adults: the 45 and up study. Journal of the American Geriatrics Society. 2012; 60(4):719-725. [PubMed: 22486736]

26. Lindau ST, Schumm LP, Laumann EO, Levinson W, O'muircheartaigh CA, Waite LJ. A study of sexuality and health among older adults in the United States. New England Journal of Medicine. 2007; 357(8):762-774. [PubMed: 17715410]

27. Henry NJ, Berg CA, Smith TW, Florsheim P. Positive and negative characteristics of marital interaction and their association with marital satisfaction in middle-aged and older couples. Psychology and aging. 2007; 22(3):428. [PubMed: 17874945]

28. Diener E. The science of well-being. Springer; 2009. Subjective well-being; 11-58.

29. Shmotkin D. Happiness in the face of adversity: Reformulating the dynamic and modular bases of subjective well-being. Review of General Psychology. 2005; 9(4):291.

30. Webb E, Blane D, McMunn A, Netuveli G. Proximal predictors of change in quality of life at older ages. Journal of Epidemiology \& Community Health. 2010 jech.2009.101758.

31. Association AP. Diagnostic and statistical manual of mental disorders: DSM-5. American Psychiatric Association; 2013.

32. Pinquart M, Sörensen S. Differences between caregivers and noncaregivers in psychological health and physical health: a meta-analysis. Psychology and aging. 2003; 18(2):250. [PubMed: 12825775]

33. Netuveli G, Wiggins RD, Hildon Z, Montgomery SM, Blane D. Quality of life at older ages: evidence from the English longitudinal study of aging (wave 1). Journal of Epidemiology \& Community Health. 2006; 60(4):357-363. [PubMed: 16537355] 
34. Center PR. America's Changing Religious Landscape: Christians Decline Sharply as Share of Population; Unaffiliated and Other Faiths Continue to Grow. Religion and Public Life. 2015

35. Mortimer JT, Shanahan MJ. Handbook of the life course. Springer Science \& Business Media; 2007.

36. Cowlishaw S, Niele S, Teshuva K, Browning C, Kendig H. Older adults' spirituality and life satisfaction: a longitudinal test of social support and sense of coherence as mediating mechanisms. Ageing \& Society. 2013; 33(7):1243-1262.

37. Thomas PA. Is it better to give or to receive? Social support and the well-being of older adults. Journals of Gerontology Series B: Psychological Sciences and Social Sciences. 2009; 65(3):351357. 


\section{Implications for Practice}

Partners of breast cancer survivors may need support coping with their spouse's/partner's cancer. Partners of younger survivors may require more support than partners of older survivors. 


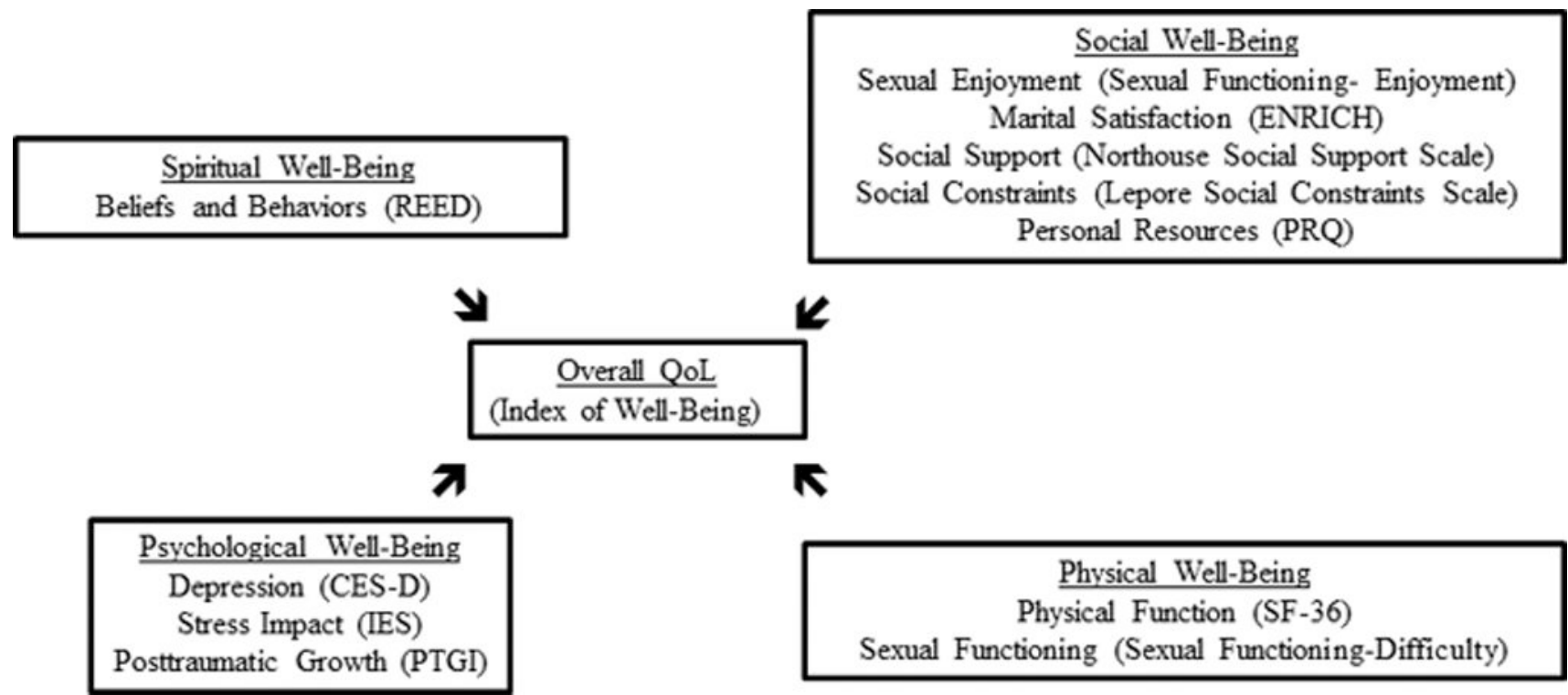

Figure 1.

Overall Quality of Life and Specific Domains for Partners of Younger Long-term Breast

Cancer Survivors and Partners of Older Long-term Breast Cancer Survivors 
Table 1

Demographic Information for and Significant Differences between Partners of Younger Breast Cancer Survivors and Partners of Older Breast Cancer Survivors Diagnosed 3-8 Years Prior

\begin{tabular}{|c|c|c|c|}
\hline Variable & $\begin{array}{c}\text { YP } \\
(n=227)\end{array}$ & $\underset{(n=281)}{\text { OP }}$ & $\begin{array}{l}\text { T-test }(p) \\
\text { between } \\
\text { YP and OP }\end{array}$ \\
\hline Race, Number (percentage) & & & 0.01 \\
\hline Caucasian & $210(92.5)$ & $278(98.9)$ & \\
\hline Black or African American & $7(3.1)$ & $3(1.1)$ & \\
\hline Asian & $2(.9)$ & 0 & \\
\hline Other & $8(3.5)$ & 0 & \\
\hline Education (years), mean $(S D)$ & $14.88(2.552)$ & $14.69(3.03)$ & 0.423 \\
\hline Highest Level of Education Completed & $\mathrm{N}(\%) \mathrm{YP}$ & $\mathrm{N}(\%) \mathrm{OP}$ & \\
\hline Graduate or Professional Degree & $38(16.7)$ & $67(24.1)$ & \\
\hline Some Graduate School & $10(4.4)$ & $15(5.4)$ & \\
\hline Bachelors Degree & $58(25.6)$ & $43(15.5)$ & \\
\hline Associates Degree & $21(9.3)$ & $18(6.5)$ & \\
\hline Some College & $31(13.7)$ & $33(11.9)$ & \\
\hline Technical or Trade School & $23(10.1)$ & $28(10.1)$ & \\
\hline High School Graduate/GED & $40(17.6)$ & $54(19.4)$ & \\
\hline Some High School & $5(2.2)$ & $13(4.7)$ & \\
\hline Elementary School or Less & 0 & $3(1.1)$ & \\
\hline Missing & $1(.4)$ & $4(1.4)$ & \\
\hline Religious Affiliation, Number (percentage) & & & 0.048 \\
\hline Christian & $189(83.6)$ & $247(89.16)$ & \\
\hline Other & $11(9.8)$ & $7(2.53)$ & \\
\hline No religious affiliation & $26(11.5)$ & $23(8.3)$ & \\
\hline Missing & $1(.44)$ & $4(.36)$ & \\
\hline Current age years, mean $(S D)$ & $48.04(7.181)$ & $67.80(6.75)$ & 0.000 \\
\hline
\end{tabular}

Abbreviations: YP, partners of younger survivors; OP, partners of older survivors; SD, standard deviation, $n$, number in sample; $p$, level of significance 


\section{Table 2}

Mean Scores, Standard Deviation, and Range for all Scales for Partners of Younger Survivors and Partners of Older Survivors

\begin{tabular}{|c|c|c|c|}
\hline Measure & $\begin{array}{l}\text { Mean (SD), Range } \\
\text { YP }\end{array}$ & $\begin{array}{l}\text { Mean }(S D) \text {, } \\
\text { Range OP }\end{array}$ & $\begin{array}{l}\operatorname{MANOVA}^{a}(p) \\
\text { between YP and OP, } \\
\text { Effect Size }^{b}\end{array}$ \\
\hline \multicolumn{4}{|l|}{ Physical } \\
\hline Physical Functioning Scale-10 & 28.117 (3.498), $11-30$ & $25.914(4.05), 11-30$ & $6.462(.000), \mathrm{ES}=-0.57$ \\
\hline Sexual Functioning Difficulty & $5.652(3.033), 3-15$ & $8.39(3.59), 3-15$ & $-9.22(.000) \mathrm{ES}=0.82$ \\
\hline \multicolumn{4}{|l|}{ Social } \\
\hline Sexual Functioning Total & $26.642(5.073), 9-35$ & $23.29(5.87), 8-35$ & $7.07(.000) \mathrm{ES}=-0.61$ \\
\hline Sexual Functioning Enjoyment & 14.297 (2.818), 6-20 & $13.67(3.04), 5-20$ & $2.58(0.01) \mathrm{ES}=-0.21$ \\
\hline ENRICH Marital Satisfaction & $51.107(12.941), 11-87.02$ & $55.63(10.19), 10-85.93$ & $-4.25(.000) \mathrm{ES}=0.39$ \\
\hline Northouse Social Support Scale & $26.608(5.241), 8-35$ & 28.08 (4.35), $16-35$ & $-3.45(.001) \mathrm{ES}=0.31$ \\
\hline Lepore Social Constraints Scale & 20.333 (6.336), $14-40$ & 19.07 (5.53), 14-47 & $2.28(.023) \mathrm{ES}=-0.21$ \\
\hline Parenting Satisfaction & $20.11(3.66), 7-25$ & $21.08(3.33), 9-25$ & $-2.93(.004) \mathrm{ES}=0.28$ \\
\hline Personal Resource Questionnaire & 79.222 (14.809), 20-105 & 80.76 (13.11), 30-105 & $-1.21(.227), \mathrm{NS}$ \\
\hline \multicolumn{4}{|l|}{ Psychological } \\
\hline Centers for Epidemiologic Studies- Depression Scale & 8.795 (8.486), 0-42 & $6.81(6.03), 0-40$ & $2.86(.003) \mathrm{ES}=-0.27$ \\
\hline Impact of Event Scale-Revised total & 10.952 (10.846), 0-49 & 8.69 (8.93), 0-59 & $2.47(.014) \mathrm{ES}=-0.23$ \\
\hline Intrusions & 4.887 (5.147), 0-22 & $3.92(4.09), 0-22$ & $2.25(.025) \mathrm{ES}=-0.21$ \\
\hline Avoidance & 3.689 (3.993), 0-23 & $3.33(3.62), 0-23$ & $1.05(.297)$ \\
\hline Hyperarousal & 2.376 (3.217), $0-15$ & 1.45 (2.42), 0-17 & $3.53(.000) \mathrm{ES}=-0.33$ \\
\hline Post Traumatic Growth Inventory & 44.103 (21.438), $0-105$ & 43.06 (24.60), $0-100$ & $.459(.646), \mathrm{NS}$ \\
\hline Relating to Others & 15.832 (7.939), $0-35$ & 16.46 (9.06), $0-35$ & $-.856(.392), \mathrm{NS}$ \\
\hline New Possibilities & 7.333 (5.436), $0-25$ & $6.44(5.69), 0-23$ & $1.73(.084), \mathrm{NS}$ \\
\hline Personal Strength & 8.537 (4.710), $0-20$ & $8.02(5.04), 0-19$ & $1.130(.259), \mathrm{NS}$ \\
\hline Spiritual Change & 3.85 (3.142), $0-10$ & $3.96(3.46), 0-10$ & $.024(.655), \mathrm{NS}$ \\
\hline Appreciation of Life & 8.57 (3.608), $0-15$ & $8.18(4.26), 0-15$ & $.003(.281), \mathrm{NS}$ \\
\hline \multicolumn{4}{|l|}{ Spiritual } \\
\hline Reed Spiritual Perspectives Scale & $3.861(1.396), 1-6$ & $4.04(1.39), 1-6$ & $-1.587(.113), \mathrm{NS}$ \\
\hline Beliefs & $4.023(1.466), 1-6$ & $4.23(1.14), 1-6$ & $-1.754(.080), \mathrm{NS}$ \\
\hline Activities & $2.874(1.423), 1-6$ & $3.23(1.52), 1-6$ & $-3.010(.003) \mathrm{ES}=0.26$ \\
\hline Behaviors & $3.613(1.462), 1-6$ & $3.76(1.52), 1-6$ & $-1.227(.220), \mathrm{NS}$ \\
\hline \multicolumn{4}{|l|}{ Overall Wellbeing } \\
\hline Index of Wellbeing & 10.747 (2.359), 3.73-14.70 & $11.75(2.29), 3.35-14.70$ & $-4.725(.000) \mathrm{ES}=0.43$ \\
\hline
\end{tabular}

${ }^{a}$ All MANOVA contrasts controlled for age and whether the partner was the same partner at time of BCS diagnosis

$b_{\mathrm{ES}}=$ difference between means divided by the pooled standard deviation

Abbreviations: YP, partners of younger survivors; OP, partners of older survivors; SD, standard deviation; ES, effect size; MANOVA, multivariate analysis of variance; NS, non-significant 
Table 3

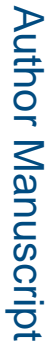

Regression Analysis for Wellbeing in Partners of Younger Survivors.

\begin{tabular}{|l|l|l|l|l|}
\hline & $\boldsymbol{B}$ & $\boldsymbol{S E} \boldsymbol{B}$ & $\boldsymbol{\beta}$ & $\boldsymbol{p}$ \\
\hline Physical Functioning & .016 & .007 & $.122^{a}$ & .022 \\
\hline Depressive Symptoms & -.074 & .018 & $-.271^{b}$ & .001 \\
\hline Marital Satisfaction & .023 & .012 & $.127^{a}$ & .05 \\
\hline Parenting Satisfaction & .107 & .039 & $.166^{a}$ & .006 \\
\hline Personal Resources & .045 & .011 & $.278^{b}$ & .001 \\
\hline $\mathrm{R}^{2}=.473(p s<.05) ; \mathrm{F}(5,195)=35.05 ; \mathrm{p}<.001$ & \\
\hline
\end{tabular}

${ }_{p<.05}$

$b_{p<.001}$ 
Table 4

Regression Analysis for Wellbeing in Partners of Older Survivors.

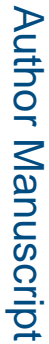

\begin{tabular}{|l|l|l|l|l|}
\hline & $\boldsymbol{B}$ & $\boldsymbol{S E} \boldsymbol{B}$ & $\boldsymbol{\beta}$ & $\boldsymbol{p}$ \\
\hline Depressive Symptoms & -.112 & .022 & $-.297^{a}$ & .001 \\
\hline Parenting Satisfaction & .134 & .040 & $.194^{a}$ & .001 \\
\hline Spirituality & .174 & .087 & $.107^{b}$ & .046 \\
\hline Social Support & .122 & .031 & $.230^{a}$ & .001 \\
\hline $\mathrm{R}^{2}=.328(p \mathrm{~s}<.05) ; \mathrm{F}(4,244)=29.80 ; \mathrm{p}<.001$ & \\
\hline
\end{tabular}

${ }^{a} p<.001$

$b_{p<.05}$ 